\title{
PLASMA LIPOPROTEIN METABOLISM IN PERFUSED RAT LIVERS. II. TRANSFER OF FREE AND ESTERIFIED CHOLESTEROL INTO THE PLASMA*
}

\author{
By PAUL S. ROHEIM, DAVID E. HAFT, LEWIS I. GIDEZ, $\dagger$ ABRAHAM WHITE, \\ AND HOWARD A. EDER
} (From the Departments of Medicine, Radiology, and Biochemistry, Albert Einstein College of
Medicine of Yeshiva University, New York, N. Y.)

(Submitted for publication February 8, 1963 ; accepted April 16, 1963)

In a previous paper (1), the synthesis and entry into the plasma of the protein moiety of the different lipoprotein classes has been described. The present studies deal with the metabolism of the free and esterified cholesterol of the lipoproteins.

Relatively little is known of the metabolism of the plasma lipids as they exist in the various lipoprotein fractions. Study of certain lipids is difficult, if not impossible, because exchange occurs among different lipoprotein fractions, and useful observations can be made only with those lipids not undergoing exchange (2). Previous studies (3-5) have shown that the in vitro exchange of ester cholesterol is slow relative to that of free cholesterol. In the present study, we labeled free and esterified cholesterol of the plasma biosynthetically and measured their equilibration between various lipoprotein fractions. After we established that there was virtually no exchange of esterified cholesterol in vitro, we examined the metabolism of this lipid fraction of the various lipoproteins.

\section{METHODS}

Animals. Male rats of the Wistar strain ${ }^{1}$ weighing 300 to $500 \mathrm{~g}$ were used as blood and liver donors in all studies except the two shown in Tables VI, VII, and VIII, in which Sprague-Dawley rats ${ }^{2}$ were used. The standard diet was one of Rockland Farm mouse pellets.

* Supported by U. S. Public Health Service training grants HTS-5273 and HTS-5265 and research grants $\mathrm{H}-2965$ and H-2832 from the National Heart Institute, Bethesda, Md., and by grants from the Life Insurance Medical Research Fund, Inc., and the American Heart Association. Presented in part at the 13th and 14th annual meetings of the Council on Arteriosclerosis of the American Heart Association, November, 1959, and October, 1960 (Circulation 1959, 20, 968 and 1960, 22, 652).

† Established Investigator, American Heart Association.

1 Camm Research Institute, Wayne, N. J.

2 Holtzman Laboratories, Madison, Wis.
When cholesterol was a dietary component (2\% of the diet), it was dissolved in olive oil and fed for 5 to 7 days, except in the experiments described in Tables VI, VII, and VIII; in those, cholesterol was fed for 12 to 14 days in order to produce livers of very high lipid content.

Liver perfusion. The technique of perfusion of Miller and associates $(6,7)$ was used. Mevalonic acid-2-C $C^{14}$ was used as sterol precursor. In some experiments, 3.3 to $5.5 \mu \mathrm{c}(0.7$ to $1.2 \mathrm{mg})$ was added directly to the perfusing blood; one-third of the total was added at the start of the experiment, and the rest, by continuous injection during the perfusion ( 2 to 4 hours). In other experiments, designed to study the transfer of labeled cholesterol from liver to plasma, $11 \mu \mathrm{c}$ of mevalonic acid-2- $\mathrm{C}^{14}$ was given in two ip injections to the rats used as liver donors, at 16 hours and 3 hours before removal of their livers.

Chylomicrons were prepared from intestinal lymph of rats that received $4 \mu \mathrm{c}$ of cholesterol-4-C $\mathrm{C}^{14}$ dissolved in olive oil by stomach tube. The lymph, obtained through a cannula inserted into an intestinal lymph vessel, was collected for 24 hours in a tube containing 100,000 U penicillin and $0.2 \mathrm{~g}$ streptomycin, diluted with $0.85 \%$ $\mathrm{NaCl}$, and spun at $114,000 \times g$ in a 40.3 rotor for 60 minutes in a Spinco model $L$ preparative ultracentrifuge. The chylomicron layer obtained from the upper $2 \mathrm{~cm}$ of the tube was resuspended in $0.85 \% \mathrm{NaCl}$ solution. This suspension was dispersed by being forced through a 26gauge needle three times. It was then centrifuged, separated, and dispersed again.

Plasma lipoprotein fractions were prepared as previously described (8). After removal of an appropriate sample for determination of total cholesterol (9), the lipid was extracted from the remainder with $2: 1$ chloroform:methanol (10), washed three times with water, and evaporated to dryness. The residue was taken up in $95 \%$ ethanol: acetone $(1: 1)$, and free cholesterol was separated as the digitonide. The supernatant fluid was evaporated to dryness, taken up in petroleum ether, and the solution again evaporated to dryness. The ester cholesterol was taken up in ethanol:acetone, saponified, and the digitonide precipitated. The digitonide precipitate was washed and dried and then dissolved in the dioxane: phosphoric acid: absolute ethanol reagent of Kabara (11). Samples of this were counted in a Packard Tri-Carb liquid scintillation spectrometer (12). Cholesterol was determined on 
another sample by use of a modified Lieberman-Burchard reagent. Cholesterol was also determined by the Sperry and Webb modification (13) of the Schoenheimer-Sperry method (14). Triglycerides were determined by Van Handel's (15) modification of the Van Handel and Zilversmit procedure (16).

For the study determining the fatty acid composition of the cholesterol esters, cholesterol esters from lipid extracts were separated from the other lipids as follows. The liver cholesterol esters were separated on a column of 100-200 mesh Unisil by the method of Horning, Williams, and Horning (17). The total cholesterol esters of lipid extracts of lipoproteins were obtained by thin-layer chromatography (18); the plates were developed in redistilled hexane: ether: glacial acetic acid $(83: 16: 1)$. The cholesterol ester bands, made visible by spraying the dried plate with $0.02 \% 2^{\prime}, 7^{\prime}$-dichlorofluorescein in ethanol, were scraped off, and the esters were eluted with three successive $15-\mathrm{ml}$ vol of ether. The methyl esters of the fatty acids of the cholesterol esters were prepared by the procedure of Stoffel, Chu, and Ahrens (19). The methyl esters were then purified by thin-layer chromatography as described above and subjected to gas chromatographic analysis on a model 10 Barber-Colman instrument equipped with a $\mathrm{Sr}^{\text {90 }}$ ionization detector. Separations were made on a 6 -foot column containing $16.1 \%$ ethylene glycol succinate on 80-100 mesh acid-washed Chromosorb $\mathrm{W}$. The column temperature was $185^{\circ} \mathrm{C}$.

\section{RESULTS}

Exchange of cholesterol in vitro. Chylomicrons containing cholesterol- $\mathrm{C}^{14}$ were mixed with whole plasma, and the mixture was incubated for 16 hours at $37^{\circ} \mathrm{C}$. In this and in subsequent studies of exchange, $100,000 \mathrm{U}$ of penicillin and $0.2 \mathrm{~g}$ of streptomycin were added to each flask. Chylomicrons were separated from this mixture, and radioactivity in the cholesterol of the chylomicrons and of the infranatant plasma was determined

TABLE I

Exchange of labeled cholesterol between lymph chylomicrons and plasma during in vitro incubation at $37^{\circ} \mathrm{C}$ for 16 hours

\begin{tabular}{cccc}
\hline \hline & & \multicolumn{2}{c}{ Specific activity } \\
\cline { 3 - 4 } & Pool size* & Initial & Final \\
\hline Free cholesterol & $m g$ & \multicolumn{2}{c}{$d p m / m g$} \\
$\quad \begin{array}{ccc}\text { Chylomicrons } \dagger \\
\text { Plasma }\end{array}$ & 1.19 & 50,500 & 10,500 \\
Esterified cholesterol & 5.10 & 0 & 10,800 \\
Chylomicrons $\dagger$ & & & \\
Plasma & 1.35 & 64,900 & 60,300 \\
& 16.80 & 0 & 360 \\
\end{tabular}

* Total amount measured at start of incubation.

† Labeled fraction.
TABLE II

Exchange of labeled cholesterol between isolated plasma lipoprotein fractions during in vitro incubation at $37^{\circ} \mathrm{C}$ for 16 hours

\begin{tabular}{cccc}
\hline \hline & & \multicolumn{2}{c}{ Specific activity } \\
\cline { 3 - 5 } Fraction & Pool size* & Initial & Final \\
\hline Free cholesterol & $m g$ & \multicolumn{2}{c}{$d p m / m g$} \\
$\mathrm{D}<1.063 \dagger$ & 1.84 & 7,000 & 4,500 \\
$\mathrm{D}>1.063$ & 0.93 & 0 & 4,400 \\
$\mathrm{D}>1.063 \dagger$ & 1.62 & 6,000 & 4,300 \\
$\mathrm{D}<1.063$ & 0.76 & 0 & 3,900 \\
Esterified cholesterol & & & \\
$\mathrm{D}<1.063 \dagger$ & 1.81 & 3,400 & 3,500 \\
$\mathrm{D}>1.063$ & 7.14 & 0 & 57 \\
$\mathrm{D}>1.063 \dagger$ & 6.60 & 1,800 & 1,500 \\
$\mathrm{D}<1.063$ & 1.49 & 0 & 200
\end{tabular}

* Total amount measured at start of incubation.

$\dagger$ Labeled fraction.

(Table I). It is apparent that the free cholesterol equilibrated completely between the chylomicrons and the plasma, whereas there was virtually no exchange of ester cholesterol. Because the plasma samples had four times as much free cholesterol as the chylomicrons, the total amount of labeled free cholesterol transferred to plasma was more than $87 \%$ of the total amount added. In contrast, the quantity of radioactive ester cholesterol found in the plasma was less than $7 \%$ of that added with the chylomicrons, and this amount could represent incomplete separation. These data are representative of several similar experiments.

Exchange of cholesterol in vitro between high-

TABLE III

Effect of time and temperature on exchange of free cholesterol between plasma lipoprotein fractions

\begin{tabular}{|c|c|c|}
\hline & \multicolumn{2}{|c|}{ Specific activity } \\
\hline & $\mathrm{D}<1.063^{*}$ & $\mathrm{D}>1.063$ \\
\hline & \multicolumn{2}{|c|}{$d p m / m g$} \\
\hline Before incubation & 10,500 & 0 \\
\hline Immediate separation & 10,400 & 1,200 \\
\hline $\begin{array}{l}\text { Incubation } 24 \text { hours } \\
\text { at } 4^{\circ} \mathrm{C}\end{array}$ & 6,400 & 1,800 \\
\hline $\begin{array}{l}\text { Incubation } 2 \text { hours } \\
\text { at } 37^{\circ} \mathrm{C}\end{array}$ & 5,200 & 3,400 \\
\hline $\begin{array}{l}\text { Incubation } 6 \text { hours } \\
\text { at } 37^{\circ} \mathrm{C}\end{array}$ & 4,200 & 4,200 \\
\hline
\end{tabular}

* Labeled fraction. 
TABLE IV

Incubation of whole plasma and blood containing labeled esterified cholesterol*

\begin{tabular}{|c|c|c|c|c|}
\hline \multirow{2}{*}{$\begin{array}{c}\text { Exp't } \\
\text { no. }\end{array}$} & \multirow{2}{*}{$\begin{array}{c}\text { Sample } \\
\text { incubated }\end{array}$} & \multirow[b]{2}{*}{ Fraction } & \multicolumn{2}{|c|}{ Specific activity } \\
\hline & & & Initial & Final \\
\hline & & & \multicolumn{2}{|c|}{$d p m / m g$} \\
\hline $55 \dagger$ & Plasma & $\begin{array}{l}\mathrm{D}<1.063 \\
\mathrm{D}>1.063\end{array}$ & $\begin{array}{l}1,900 \\
3,400\end{array}$ & $\begin{array}{l}1,850 \\
3,500\end{array}$ \\
\hline \multirow[t]{2}{*}{62} & Plasma & $\begin{array}{l}\mathrm{D}<1.063 \\
\mathrm{D}>1.063\end{array}$ & $\begin{array}{r}420 \\
1,800\end{array}$ & $\begin{array}{r}580 \\
1,900\end{array}$ \\
\hline & Blood & $\begin{array}{l}D<1.063 \\
D>1.063\end{array}$ & $\begin{array}{r}420 \\
1,800\end{array}$ & $\begin{array}{r}600 \\
2,000\end{array}$ \\
\hline $75 \ddagger$ & Plasma & $\begin{array}{l}\mathrm{D}<1.063 \\
\mathrm{D}>1.063\end{array}$ & $\begin{array}{r}2,020 \\
500\end{array}$ & $\begin{array}{r}2,280 \\
480\end{array}$ \\
\hline \multirow[t]{2}{*}{$82 \ddagger$} & Plasma & $\begin{array}{l}\mathrm{D}<1.063 \\
\mathrm{D}>1.063\end{array}$ & $\begin{array}{r}2,000 \\
390\end{array}$ & $\begin{array}{r}1,870 \\
380\end{array}$ \\
\hline & Blood & $\begin{array}{l}\mathrm{D}<1.063 \\
\mathrm{D}>1.063\end{array}$ & $\begin{array}{r}2,000 \\
390\end{array}$ & $\begin{array}{r}1,400 \\
360\end{array}$ \\
\hline
\end{tabular}

${ }^{*}$ In experiment 55 , the liver donor was preinjected with $\mathrm{H}^{3}$-acetate. In experiment 62 , mevalonate-2- $\mathrm{C}^{14}$ was added during the perfusion. In experiments 75 and 82, the liver donor was preinjected with mevalonate-2-C $\mathrm{C}^{14}$.

$\dagger$ Incubation for 4 hours at $37^{\circ} \mathrm{C}$. All other incubations were for 16 hours at $37^{\circ} \mathrm{C}$.

$\ddagger$ Cholesterol-fed liver donor used.

and low-density lipoproteins was also measured (Table II). These fractions were labeled biosynthetically by perfusion of the livers of rats that received mevalonic acid-2- $\mathrm{C}^{14} 3$ hours before sacrifice. In addition, mevalonic acid-2-C $\mathrm{C}^{14}$ was added to the perfusate. The lipoproteins were separated into two fractions $(\mathrm{D}<1.063$ and $>$ $1.063)$; a labeled $\mathrm{D}<1.063$ fraction was then mixed with an unlabeled $\mathrm{D}>1.063$ fraction, and a labeled $\mathrm{D}>1.063$ fraction was mixed with an unlabeled $\mathrm{D}<1.063$ fraction. The mixtures were incubated for 16 hours at $37^{\circ} \mathrm{C}$ and the lipoproteins separated into two fractions by centrifugation at $\mathrm{D}=1.063$. Each fraction was resuspended in a solution of $D=1.063$, and the lipoproteins were again separated by ultracen- trifugation. Table II shows that there was complete equilibration of the free cholesterol between these two lipoprotein fractions, whereas there was virtually no exchange of esterified cholesterol.

Table III shows the results of incubation for varying periods at two temperatures on the exchange of free cholesterol. Complete equilibration of free cholesterol occurred between 2 and 6 hours of incubation at $37^{\circ} \mathrm{C}$, but was not attained even after 24 hours of incubation at $4^{\circ} \mathrm{C}$.

To exclude the possibility that the lack of exchange in the previous studies could in some way be due to alteration of the lipoproteins during separation, whole plasma was obtained in which the biosynthetically labeled ester cholesterol had markedly different specific activities in the two lipoprotein fractions. When these samples were incubated and the lipoproteins separated, no exchange could be demonstrated (Table IV). The free cholesterol had the same specific activity in the lipoprotein fractions, and this was unaltered on incubation.

Entry of cholesterol into the perfusate. When livers from rats fed standard diets were perfused for 2 to 4 hours, the cholesterol concentration of the perfusate was unchanged. When, however, livers from cholesterol-fed rats were perfused, the cholesterol concentration in the perfusate rose by an average of $9.2 \mathrm{mg}$ per $100 \mathrm{ml}$, representing a net transfer of $8.7 \mathrm{mg}$ of cholesterol from the liver to the perfusate (Table V). Table VI shows the results of a single experiment where the conditions were altered as previously indicated (see Methods) and where the increase in cholesterol of the perfusate was greater than in the experiments shown in Table V. When the increment in each of the three lipoprotein fractions was measured, it was found that a large proportion of the cholesterol added to the perfusate was in the $\mathrm{D}<1.019$ fraction of lipoproteins $(85 \%)$, whereas the incre-

TABLE V

Changes in cholesterol concentration in perfusate plasma

\begin{tabular}{|c|c|c|c|}
\hline \multirow[b]{2}{*}{ Diet of liver donor } & \multicolumn{3}{|c|}{ Cholesterol concentrations } \\
\hline & Initial & Final & Difference \\
\hline $\begin{array}{l}\text { Normal }[16]^{*} \\
\text { High cholesterol }[17]\end{array}$ & $\begin{array}{l}40.8 \pm 1.3 \\
43.2 \pm 1.6\end{array}$ & $\begin{array}{r}m g / 100 m l \\
40.1 \pm 1.6 \\
52.4 \pm 1.9\end{array}$ & $\begin{array}{l}-0.7 \pm 0.7 \\
+9.2 \pm 0.9 \dagger\end{array}$ \\
\hline
\end{tabular}

* Number of experiments is given in brackets. Data are expressed as mean $\pm \mathrm{SE}$.

$\dagger$ Different from normal average with $p<.001$. 
TABLE VI

Changes in cholesterol concentration in plasma lipoprotein fractions during perfusion of liver from cholesterol-fed donor

\begin{tabular}{lrrr}
\hline \hline & \multicolumn{3}{c}{ Total cholesterol concentration } \\
\cline { 2 - 5 } & Initial & Final & Difference \\
\hline & \multicolumn{4}{c}{$m g / 100$} & $m l$ \\
Total plasma & 48.9 & 95.6 & +46.7 \\
D $<1.019$ & 5.3 & 38.5 & +33.2 \\
$\mathrm{D}=1.019-1.063$ & 7.8 & 13.3 & +5.5 \\
$\mathrm{D}>1.063$ & 35.9 & 38.1 & +2.2 \\
\hline
\end{tabular}

ments in the other fractions were relatively small.

The $\mathrm{D}<1.019$ fraction is heterogeneous. Therefore, in another experiment (Table VII) in which the liver from a cholesterol-fed rat was used, a $\mathrm{D}<1.006$ fraction was separated and analyzed for cholesterol and triglyceride. Despite significant increase during perfusion of the cholesterol and triglyceride concentrations of the perfusate, there was virtually no increase in lipid in the $\mathrm{D}<1.006$ fraction. All of the increase was in the $\mathrm{D}>1.006$ fraction. This observation and the previous findings indicate that all the newly released lipoproteins are in the $\mathrm{D}=1.006$ to 1.019 fraction, and there is apparently no release of chylomicrons under these conditions.

In the rat fed a normal diet, Swell, Law, Field, and Treadwell (20) and Goodman (5) have shown that the fatty acid composition of the plasma cholesterol esters differs markedly from that of the liver cholesterol esters: in the liver cholesterol esters, the major fatty acids are palmi-

TABLE VII

Changes in concentration of triglyceride and cholesterol in $D<1.006$ and $D>1.006$ lipoprotein fractions during perfusion of liver from cholesterol-fed donor*

\begin{tabular}{|c|c|c|c|c|}
\hline & \multicolumn{2}{|c|}{ Triglyceride } & \multicolumn{2}{|c|}{ Cholesterol } \\
\hline & $\mathrm{D}<1.006$ & $\mathrm{D}>1.006$ & $\mathrm{D}<1.006$ & $\mathrm{D}>1.006$ \\
\hline & \multicolumn{2}{|c|}{$m g / 100 m l$} & \multicolumn{2}{|c|}{$m g / 100 \mathrm{ml}$} \\
\hline $\begin{array}{l}\text { Beginning } \\
\text { End }\end{array}$ & $\begin{array}{l}6.5 \\
6.2\end{array}$ & $\begin{array}{l}29.8 \\
51.2\end{array}$ & $\begin{array}{l}0.08 \\
1.6\end{array}$ & $\begin{array}{l}44.5 \\
72.7\end{array}$ \\
\hline Increment & -.3 & 21.4 & 1.5 & 28.2 \\
\hline
\end{tabular}

* Plasma samples were delivered under a layer of dilute $\mathrm{NaCl}(\mathrm{D}=1.006)$ and spun for 30 minutes at $30,000 \times g$ in a 40.3 rotor in a Spinco model L preparative ultracentrifuge. The top layer was then redispersed in saline solution $(D=1.006)$ and the mixture recentrifuged; this washing procedure was repeated twice more. All the infranatant fluids were combined as the $D>1.006$ fraction. tate, stearate, and oleate, whereas arachidonate and linoleate predominate in the plasma cholesterol esters. We measured the fatty acid composition of the cholesterol esters of the liver of a cholesterol-fed rat and of the plasma lipoprotein fractions before and after perfusion. Table VIII gives the data together with the fatty acid composition of the cholesterol esters of rats fed the normal diet. The liver from the cholesterol-fed rat differs from the normal in that the sterol ester is mainly cholesterol oleate (21). After perfusion, there was a more than fivefold increase in the cholesterol oleate in the $\mathrm{D}<1.019$ lipoproteins, so that the sterol ester pattern became similar to that of the liver. It is noteworthy that the initial fatty acid pattern of the cholesterol esters in the $\mathrm{D}<1.019$ fraction is similar to that found in the normal liver, whereas the other fractions differ considerably. These findings suggest that the cholesterol esters in the $\mathrm{D}<1.019$ fraction are randomly derived from the total cholesterol esters in the liver.

The transfer of cholesterol from the liver to the perfusate was also studied by measurement of the incorporation of liver cholesterol- $\mathrm{C}^{14}$ into the plasma lipoprotein fractions. In most experiments, livers were obtained for perfusion from rats injected with mevalonic acid-2-C $\mathrm{C}^{14} 16$ and 3 hours before sacrifice. This method of administration was chiefly used because the specific activity of liver cholesterol remained rather constant during the perfusion, since there was no further incorporation of mevalonic acid. The major process occurring was the transfer of cholesterol between liver and plasma. When the precursor was added during perfusion, as in a few experiments, there was continuing synthesis of labeled cholesterol, and the interpretation of the data was more difficult.

In the first group of experiments, two lipoprotein fractions were separated, $\mathrm{D}<1.063$ and $\mathrm{D}=$ 1.063 to 1.21 (Tables IX and X). It was found that the specific activity of free cholesterol in the two fractions tended to be similar, as is to be expected from the finding that free cholesterol readily reaches isotopic equilibrium in vitro. On the other hand, the specific activity of cholesterol ester was considerably higher in the $D=1.063$ to 1.21 fractions when the precursor was added during the perfusion, and slightly higher in three of 
TABLE VIII

Fatty acid composition of cholesterol esters of perfusate plasma lipoproteins before and after perfusion of liver of cholesterol-fed rat

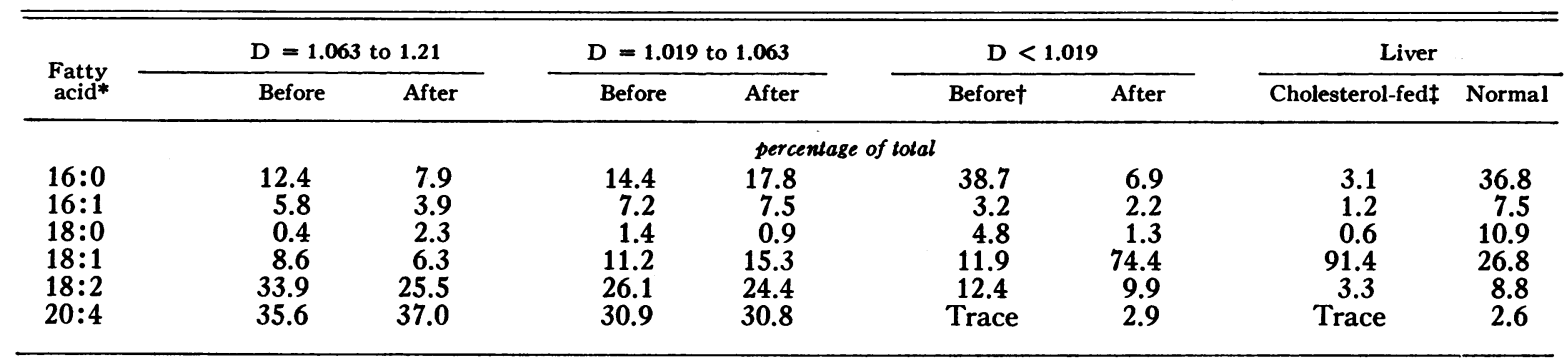

* Number of carbon atoms : number of double bonds.

In similar analyses of the $D<1.019$ lipoproteins isolated from pooled plasma of other groups of rats, the acids listed in the table comprised 94 to $99 \%$ of the total acids. In this particular sample, however, these acids comprised only $71 \%$ of the total, and the remainder consisted of $20: 1$ and appreciable amounts of unidentified unsaturated acids with chain lengths of 20 and 22 carbon atoms. These same acids were present in smaller amounts in some of the other fractions.

$\ddagger$ Analyzed at the end of the perfusion.

four experiments in which it was preinjected (Table IX).

In experiments with livers from cholesterol-fed rats (Table $\mathrm{X}$ ), there was a reduction of specific activity of free cholesterol in both the $D<1.063$ and the $D=1.063$ to 1.21 fractions and a reduction in specific activity of ester cholesterol in the latter fraction. This was undoubtedly due to the inhibition of cholesterol biosynthesis occurring with cholesterol feeding. The specific activity of ester cholesterol in the $\mathrm{D}<1.063$ fraction, how- ever, was reduced far less, and the ratio of specific activity of ester cholesterol in the $\mathrm{D}<1.063$ fraction to that in the $\mathrm{D}=1.063$ to 1.21 fraction increased more than three times. This can be explained by increased transfer of labeled cholesterol ester from the liver to the $D<1.063$ fraction.

As indicated by chemical data ( 8 ) and by previous studies dealing with lipoprotein protein synthesis (1), the $\mathrm{D}<1.063$ lipoproteins are heterogeneous. When fractions of $D=1.019$ to 1.063 and $\mathrm{D}<1.019$ were separated, they were found

TABLE IX

Specific activity of free and esterified cholesterol in perfusate lipoprotein fractions (normal liver donors)

\begin{tabular}{|c|c|c|c|}
\hline $\begin{array}{l}\text { Administration of } \\
\text { mevalonic acid-2-C }\end{array}$ & Exp't no. & $\mathrm{D}=1.063$ to 1.21 & $\mathrm{D}<1.063$ \\
\hline Free cholesterol & \multicolumn{3}{|c|}{$d p m / m g$ cholesterol } \\
\hline Infused & $\begin{array}{l}62 \\
65 \\
66 \\
70\end{array}$ & $\begin{array}{l}18,900 \\
5,850 \\
13,000 \\
40,900\end{array}$ & $\begin{array}{r}20,900 \\
5,820 \\
14,400 \\
45,600\end{array}$ \\
\hline Preinjected & $\begin{array}{l}61 \\
74 \\
78 \\
98\end{array}$ & $\begin{array}{r}1,650(.46) \\
11,700(.44) \\
4,730(.16) \\
6,000\end{array}$ & $\begin{array}{r}1,720(.48) \\
13,200(.50) \\
7,830(.26) \\
7,100\end{array}$ \\
\hline \multicolumn{4}{|c|}{ Esterified cholesterol } \\
\hline Infused & $\begin{array}{l}62 \\
65 \\
66 \\
70\end{array}$ & $\begin{array}{r}1,790 \\
230 \\
2,010 \\
13,500\end{array}$ & $\begin{array}{r}420 \\
30 \\
1,100 \\
3,500\end{array}$ \\
\hline Preinjected & $\begin{array}{l}61 \\
74 \\
78 \\
98\end{array}$ & $\begin{array}{r}820(.18) \\
4,660(.17) \\
1,770(.07) \\
1,800\end{array}$ & $\begin{array}{r}610(.13) \\
3,310(.12) \\
1,630(.06) \\
3,300\end{array}$ \\
\hline
\end{tabular}

* Values in parentheses are the ratios of the specific activity of free or ester cholesterol in the lipoprotein fractions to that in the liver at the end of perfusion. 
TABLE $\mathrm{X}$

Specific activity of free and esterified cholesterol in perfused lipoprotein fractions (cholesterol-fed liver donors preinjected with mevalonic acid-2-C ${ }^{14}$ )

\begin{tabular}{lcr}
\hline \hline Exp't no. & $\mathrm{D}=1.063$ to 1.21 & $\mathrm{D}<1.063$ \\
\hline \multicolumn{3}{c}{$d p m / m g$ cholesterol } \\
Free cholesterol & \multicolumn{1}{c}{} \\
63 & $850(.41)^{*}$ & $920(.44)$ \\
68 & $1,530(.49)$ & $1,680(.53)$ \\
75 & $3,280(.47)$ & $3,370(.48)$ \\
82 & $1,960(.43)$ & $2,860(.63)$ \\
Esterified cholesterol & \\
63 & $220(.38)$ & $580(1.00)$ \\
68 & $440(.35)$ & $1,090(.86)$ \\
75 & $500(.08)$ & $2,020(.31)$ \\
82 & $400(.12)$ & $2,000(.61)$ \\
\hline
\end{tabular}

* Values in parentheses are the ratios of the specific activity in the lipoprotein fractions to that of the liver cholesterol at the end of perfusion.

to have markedly different relative rates of turnover, judged from their specific activities (Table $\mathrm{XI}$ ). As was to be expected, the specific activity of free cholesterol tended to be similar in all three lipoproteins, although there was somewhat higher activity in the $\mathrm{D}<1.019$ lipoprotein fraction. The specific activity of ester cholesterol was much higher in the $D<1.019$ fraction than in the other fractions, a finding of interest, since its protein also has the most rapid turnover of all the lipoprotein classes (1). In the two perfusions with livers from cholesterol-fed rats, this difference was accentuated. It is apparent that the previous finding of relatively high specific activity in the cholesterol esters of the $\mathrm{D}<1.063$ fraction after cholesterol feeding is due to the $\mathrm{D}<1.019$ component included in it.

\section{DISCUSSION}

The observations reported in this paper on the in vitro exchange of cholesterol agree with previous studies indicating that free cholesterol exchanges freely among all lipoprotein fractions in vitro, but that there is virtually no exchange of ester cholesterol (3-5). Since phosphatides (22) and triglycerides (23) exchange in vitro, it would appear that the mode of attachment of ester cholesterol to the remainder of the lipoprotein complex differs from that of other lipids. The mechanism of in vitro exchange of lipid among the lipoprotein classes is unknown.

Because ester cholesterol does not exchange among the lipoprotein fractions, it is possible that study of the turnover of ester cholesterol in the various lipoproteins may provide information about the metabolism of the lipid moiety of lipoprotein molecules. It has been demonstrated that the rate of turnover of the cholesterol esters in the various lipoproteins, as estimated by their specific activity, was most rapid in the very low-density $(D<1.019)$ fraction. Since the protein in this fraction turns over considerably more rapidly than in other lipoproteins (1), it appears that protein and lipid turnover may be related. After cholesterol feeding, however, with the resulting pro-

TABLE XI

Specific activity of free and esterified cholesterol in perfused lipoprotein fractions after subfractionation of the low-density lipoproteins (liver donor rats preinjected with mevalonic acid-2-C ${ }^{14}$ )

\begin{tabular}{|c|c|c|c|c|}
\hline Diet of liver donor & Exp't no. & $\mathrm{D}=1.063$ to 1.21 & $\mathrm{D}=1.019$ to 1.063 & $\mathrm{D}<1.019$ \\
\hline & & & $d p m / m g$ cholesterol & \\
\hline \multicolumn{5}{|l|}{ Free cholesterol } \\
\hline Normal & $\begin{array}{l}88 \\
94\end{array}$ & $\begin{array}{l}3,360(.39)^{*} \\
4,030(.17)\end{array}$ & ${ }_{\dagger}^{3,760}(.44)$ & $\begin{array}{l}4,170(.49) \\
8,010(.33)\end{array}$ \\
\hline High cholesterol & $\begin{array}{l}87 \\
95\end{array}$ & $\begin{array}{l}940(.41) \\
430(.17)\end{array}$ & $\begin{array}{l}980(.43) \\
530(.20)\end{array}$ & $\begin{array}{r}1,050(.46) \\
800(.31)\end{array}$ \\
\hline \multicolumn{5}{|l|}{ Esterified cholesterol } \\
\hline Normal & $\begin{array}{l}88 \\
94\end{array}$ & $\begin{array}{l}1,130(.23) \\
1,100(.10)\end{array}$ & $\begin{array}{l}340(.07) \\
830(.08)\end{array}$ & $\begin{array}{l}2,470(.50) \\
2,930(.28)\end{array}$ \\
\hline High cholesterol & $\begin{array}{l}87 \\
95\end{array}$ & $\begin{array}{l}210(.08) \\
170(.12)\end{array}$ & $\begin{array}{l}290(.10) \\
240(.18)\end{array}$ & $\begin{array}{l}1,730(.62) \\
1,230(.91)\end{array}$ \\
\hline
\end{tabular}

* Values in parentheses are the ratios of the specific activity in the lipoprotein fraction to that of the liver cholesterol at the end of perfusion.

† Sample lost. 
found reduction of cholesterol synthesis, the transfer of cholesterol and other lipids into the plasma lipoproteins is enhanced. These findings emphasize that the formation of plasma lipoproteins is independent of the rate of formation of its lipid constituents.

Several processes are involved in the transfer of ester cholesterol from liver to plasma. With normal livers, there is transfer of labeled ester cholesterol into the plasma without an increase in the plasma ester cholesterol concentration. When livers from cholesterol-fed animals are perfused, the concentration of the very low-density lipoproteins is increased (net transfer). The data showing that in the cholesterol esters in the $\mathrm{D}<1.019$ lipoproteins there is a higher proportion of oleate, a fatty acid characteristic of liver esters, suggest that there is a direct nonselective transfer of cholesterol esters from the liver to the very low-density lipoproteins. Further evidence for this conclusion is that in these experiments, the specific activity of the cholesterol esters in the very lowdensity lipoproteins aproached that of the liver (Table XI). Since there was little cholesterol in that fraction at the beginning of the experiment (Table VI), the esters recovered at the end of the perfusion must therefore represent transfer en bloc from the liver. The striking similarity in cholesterol ester composition between the $\mathrm{D}<$ 1.019 lipoprotein and the liver of the normal rat suggests that such transfer may also occur under normal conditions. This observation can only be made in the case of the cholesterol esters because they do not exchange between the lipoprotein fractions. Lindgren, Nichols, and Wills (24) carried out a study of the fatty acid composition of the different lipid classes in the lipoprotein fractions in man, and these data show that only in the cholesterol esters are there consistent differences between the lipoprotein fractions. The triglycerides and phosphatides do not show such differences, undoubtedly because they, unlike the cholesterol esters, exchange readily between the lipoprotein fractions.

With respect to triglycerides, the net transfer into the $\mathrm{D}>1.006$ fraction from the liver of the cholesterol-fed rat (Table VII) appears to conflict with the data of Havel, Felts, and Van Duyne (23), who demonstrated that rabbits incorporated newly synthesized triglyceride most readily into the very low-density $(\mathrm{D}<1.006)$ lipoprotein. The discrepancy may be due to the ultracentrifugation for 15 hours at $115,000 \times g$ by these authors, whereas in these studies, the centrifugation at $\mathrm{D}=1.006$ was carried out for 30 minutes at $30,000 \times g$. Recent studies in our laboratory have shown that centrifugation of normal rat plasma at $\mathrm{D}=1.006$ for 20 hours at $115,000 \times g$ results in the flotation of as much cholesterol and triglyceride as does centrifugation at $\mathrm{D}=1.019$ under the same conditions (25). Furthermore, it can be calculated from the nomogram of Dole and Hamlin (26) that our D $<1.019$ fraction is composed of particles with $\mathrm{S}_{\mathrm{f}}>12$, whereas under the conditions of Havel and co-workers, the $\mathrm{D}<1.006$ fraction contains particles of $\mathrm{S}_{\mathrm{t}}>25$. Upon centrifugation at $\mathrm{D}=1.006$ for 30 minutes and $30,000 \times g$, only particles of $\mathrm{S}_{\mathrm{f}} 2,000$ would float. Thus the $\mathrm{D}<1.019$ fraction isolated in these studies is similar to that obtained by Havel and associates by prolonged centrifugation at $\mathrm{D}=1.006$.

For the two lipoprotein fractions of $\mathrm{D}>1.019$, the origin of the ester cholesterol is less certain. Since these esters contained radioactive cholesterol in considerable amounts, they were derived at least in part from the liver. One possibility is that some cholesterol esters of the liver were incorporated directly into the lipoproteins. This is consistent with the fact that the specific activity of cholesterol ester in these lipoproteins was less than that of the liver ester cholesterol and considerably lower than that of the liver free cholesterol (Table XI). On the other hand, as previously mentioned, the fatty acid composition of these cholesterol esters differs markedly from that of the liver cholesterol esters both in the control and cholesterol-fed livers. The liver esters are low in polyunsaturated acids, whereas the lipoprotein cholesterol esters are high in linoleate and especially in arachidonate. If the cholesterol esters of these lipoproteins do come from the liver, there are several possible explanations for the altered fatty acid composition: 1) the unsaturated acid esters may be preferentially incorporated into the lipoproteins, 2) these lipoproteins might derive from a pool with a cholesterol ester composition different from that of total liver cholesterol, 3) there may be selective removal by the tissues of certain esters from individual lipoproteins, or 
4) the plasma cholesterol esters, except those in the very low-density lipoprotein fraction, may derive from the free cholesterol, with esterification occurring either just before release of the lipoproteins from the liver or in the plasma itself. During in vitro incubation of whole plasma of several species, esterification of free cholesterol occurs $(27,28)$. In the studies of Glomset, Parker, Tjaden, and Williams (28), however, citrate was used as the anticoagulant, whereas in the present study heparin was used. We have found that esterification of free cholesterol over 24 hours is much slower in heparinized rat plasma than in citrated plasma. These findings may be explained by the observations of Ratti and Bianchi (29) that heparin and also calcium ions inhibit the esterase activity in human serum. It is unlikely that this process plays an important role under the condition of these studies. The reaction is slow, and during the periods used, only a small percentage of the free cholesterol would be esterified $(29,30)$. In experiments $62,65,66$, and 70 (Table IX), in which mevalonic acid was infused, the specific activity of free cholesterol was so much higher than that of esterified cholesterol that it is unlikely that significant esterification occurred. In experiments $61,74,78$, and 98 in which preinjection of mevalonate- $\mathrm{C}^{14}$ caused the liver-esterified cholesterol to acquire a substantial amount of radioactivity before the start of the perfusion, the labeling of the lipoprotein cholesterol esters was considerably more than could be explained by this slow reaction. In fact, these findings are more in accordance with the view that the liver cholesterol esters are the major source of the esters in the plasma.

Although these experiments shed no light on the biological role of the heavier lipoprotein classes, they do suggest that, in the rat, lipoproteins of $D=1.006$ to 1.019 serve as a vehicle for bulk transfer of cholesterol and triglyceride from the liver, especially when the hepatic concentration of these lipids has been increased by dietary means.

\section{SUM MARY}

The rat liver perfusion technique has been used to study the metabolism of the free and esterified cholesterol of the plasma lipoproteins. Ester cholesterol, unlike free cholesterol, fails to exchange between lipoprotein fractions in vitro. This property makes ester cholesterol a unique indicator of lipoprotein metabolism in vivo.

Perfusion of livers of cholesterol-fed rats resulted in a highly significant increase in cholesterol concentration in the perfused plasma measured after 2 to 4 hours. Study of the separated lipoprotein fractions revealed that all of this increase occurred in the fraction of $\mathrm{D}=1.006$ to 1.019. Gas chromatographic analysis showed that most of the transferred cholesterol ester was the oleate, which predominates in the livers of the cholesterol-fed rats, so that by the end of the perfusion, the sterol ester composition of the $D<$ 1.019 lipoprotein became similar to that of the perfused liver. Even under conditions of normal feeding, the fatty acid composition of the cholesterol esters of the $\mathrm{D}<1.019$ lipoproteins resembles that in the liver.

The transfer of radioactive cholesterol ester from liver to plasma was studied in perfusions in which the liver esters were labeled by administration of mevalonic acid-2-C ${ }^{14}$. The cholesterol esters isolated from the $\mathrm{D}<1.019$ fraction had the highest specific activity of all the lipoproteins at the end of perfusions with livers from either normal or cholesterol-fed rats. This fraction therefore appears to have the most rapid turnover of both its lipid and protein constituents.

The results of these studies are consistent with the concept that the cholesterol esters of the $\mathrm{D}<$ 1.019 lipoproteins are derived by direct, nonselective transfer of cholesterol esters from the liver. The cholesterol esters of the $D=1.019$ to 1.063 and the 1.063 to 1.21 lipoproteins are derived from the liver cholesterol esters by a process that is slower and selective with respect to individual esters.

\section{ACKNOWLEDGMENTS}

The authors acknowledge the competent assistance of Mrs. Libby Miller and Mrs. Ann Lorenz.

\section{REFERENCES}

1. Haft, D. E., P. S. Roheim, A. White, and H. A. Eder. Plasma lipoprotein metabolism in perfused rat livers. I. Protein synthesis and entry into the plasma. J. clin. Invest. 1962, 41, 842.

2. Lindgren, F. T., and A. V. Nichols. Structure and function of human serum lipoproteins in The 
Plasma Proteins, F. W. Putnam, Ed. New York, Academic Press, 1960, vol. 2, p. 1.

3. Biggs, M. W., D. Kritchevsky, D. Colman, J. W. Gofman, H. B. Jones, F. T. Lindgren, G. Hyde, and T. P. Lyon. Observations on the fate of ingested cholesterol in man. Circulation 1952, 6, 359.

4. Fredrickson, D. S., D. L. McCollester, R. J. Havel, and $\mathrm{K}$. Ono. The early steps in transport and metabolism of exogenous triglyceride and cholesterol in Chemistry of Lipides as Related to Atherosclerosis, I. H. Page, Ed. Springfield, Mass., Charles C Thomas, 1958, p. 205.

5. Goodman, D. S. The metabolism of chylomicron cholesterol ester in the rat. J. clin. Invest. 1962, 41, 1886.

6. Miller, L. L., C. G. Bly, M. L. Watson, and W. F. Bale. The dominant role of the liver in plasma protein synthesis. A direct study of the isolated perfused rat liver with the aid of lysine- $\epsilon-C^{14}$. J. exp. Med. 1951, 94, 431.

7. Green, M., and L. L. Miller. Protein catabolism and protein synthesis in perfused livers of normal and alloxan-diabetic rats. J. biol. Chem. 1960, 235, 3202.

8. Havel, R. J., H. A. Eder, and J. H. Bragdon. The distribution and chemical composition of ultracentrifugally separated lipoproteins in human serum. J. clin. Invest. 1955, 34, 1345.

9. Abell, L. L., B. B. Levy, B. B. Brodie, and F. E. Kendall. A simplified method for the estimation of total cholesterol in serum and demonstration of its specificity. J. biol. Chem. 1952, 195, 357.

10. Folch, J., I. Ascoli, M. Lees, J. A. Meath, and F. N. LeBaron. Preparation of lipide extracts from brain tissue. J. biol. Chem. 1951, 191, 833.

11. Kabara, J. J. A quantitative micromethod for the isolation and liquid scintillation assay of radioactive free and ester cholesterol. J. Lab. clin. Med. 1957, 50, 146.

12. Myant, N. B., and H. A. Eder. The effect of biliary drainage upon the synthesis of cholesterol in the liver. J. Lipid Res. 1961, 2, 363.

13. Sperry, W. M., and M. Webb. A revision of the Schoenheimer-Sperry method for cholesterol determination. J. biol. Chem. 1950, 187, 97.

14. Schoenheimer, R., and W. M. Sperry. A micromethod for the determination of free and combined cholesterol. J. biol. Chem. 1934, 106, 745.
15. Van Handel, E. Suggested modifications of the micro determination of triglycerides. Clin. Chem. 1961, 7, 249.

16. Van Handel, E., and D. B. Zilversmit. Micromethod for the direct determination of serum triglycerides. J. Lab. clin. Med. 1957, 50, 152.

17. Horning, M. G., E. A. Williams, and E. C. Horning. Separation of tissue cholesterol esters and triglycerides by silicic acid chromatography. J. Lipid Res. 1960, 1, 482.

18. Mangold, H. K. Thin-layer chromatography of lipids. J. Amer. Oil Chem. Soc. 1961, 38, 708.

19. Stoffel, W., F. Chu, and E. H. Ahrens, Jr. Analysis of long-chain fatty acids by gas-liquid chromatography. Analyt. Chem. 1959, 31, 307.

20. Swell, L., M. D. Law, H. Field, Jr., and C. R. Treadwell. Cholesterol ester fatty acids in serum and liver of normal and lymph-fistula rats. J. biol. Chem. 1960, 235, 1960.

21. Klein, P. D., and R. A. Martin. Some transitory changes in cholesterol metabolism induced by dietary cholesterol. J. biol. Chem. 1959, 234, 3129.

22. Eder, H. A. The lipoproteins of human serum. Amer. J. Med. 1957, 23, 269.

23. Havel, R. J., J. M. Felts, and C. M. Van Duyne. Formation and fate of endogenous triglycerides in blood plasma of rabbits. J. Lipid Res. 1962, 3, 297.

24. Lindgren, F. T., A. V. Nichols, and R. D. Wills. Fatty acid distributions in serum lipids and serum lipoproteins. Amer. J. clin. Nutr. 1961, 9, 13.

25. Switzer, S. Personal communication.

26. Dole, V. P., and J. T. Hamlin III. Particulate fat in lymph and blood. Physiol. Rev. 1962, 42, 674.

27. Sperry, W. M. Cholesterol esterase in blood. J. biol. Chem. 1935, 111, 467.

28. Glomset, J. A., F. Parker, M. Tjaden, and R. H. Williams. The esterification in vitro of free cholesterol in human and rat plasma. Biochim. biophys. Acta (Amst.) 1962, 58, 398.

29. Ratti, G., and P. Bianchi. Ricerche sulla colesterolesterasi serica: evidenziazíone dell'azione inibente dei calcio ioni. Atti Soc. lombarda Sci. med.-biol. 1957, 12, 163.

30. Rowen, R., and J. Martin. Enhancement by extracts of group A streptococci of the spontaneous esterification of cholesterol in human serum. Fed. Proc. 1962, 21, 281 (C). 